Iivari and Kinnula (2016) - This is an author version of the accepted article

\title{
'It Has to Be Useful for the Pupils, of Course' - Teachers as Intermediaries in Design with Children
}

\author{
Netta Iivari and Marianne Kinnula \\ INTERACT Research Unit, Faculty of Information Technology and Electrical Engineering, University of Oulu, P.O. BOX 3000, \\ 90014 Oulu, Finland \\ firstname.lastname@oulu.fi
}

\begin{abstract}
We explore ways by which teachers act as intermediaries in information technology (IT) design with children through analyzing three of our design projects conducted with schoolchildren and their teachers. In our projects the teachers acted as informants and evaluators, but not as IT design partners, albeit they had a lot of decision-making power as steering-group members of the projects. The teachers offered valuable understanding of children through their general knowledge about child development and their knowledge of their class. Teachers also acted as valuable facilitators in the design process, enhancing children's participation in the design process. They also acted as advocates of children and their learning. They considered children's learning goals and fit with the curriculum and developed their own skills and knowledge to serve children's learning. Occasionally, they also acted as advocates of children's interests more generally; however, not in the sense of critical tradition.
\end{abstract}

Keywords: School, children, teachers, intermediary

\section{Introduction}

When designing information technology (IT), it is pivotal to invite users into the design process. In information systems (IS) research, user participation has been one of the central themes for decades [18]. Especially user participation has been highlighted in the Scandinavian tradition [8] and more recent participatory design (PD) tradition [30]. The whole existence of the discipline of Human Computer Interaction (HCI) has also been legitimized through the rhetoric on 'representing the users' [2]. These disciplines and traditions share the assumption that users need to be involved in the design process. Another shared assumption concerns the need of various kinds of intermediaries to cater for users' needs and to facilitate users' participation in the design process. In HCI, PD and IS research, there is on-going discussion related to such intermediaries. Even during the early days of IS research, not only workers and systems designers were expected to collaborate but trade unions were also needed [8]. In the more recent literature a variety of intermediaries has been brought up [14][30][31].

Today, systems are no longer designed only for workers, their work practices, and the workplace, but instead for a variety of people with a diversity of needs within an array of contexts of use (e.g. [16][18] [30]), e.g. for children [4]. The Interaction Design and Children (IDC) research community has specifically concentrated on the research topic of IT design for and with children. Within this community, IT solutions and design methods suitable for children have been introduced, allowing and supporting children's participation in the design process [33]. IDC researchers have also contemplated on the role of other parties potentially needed in the design process. One such party is teachers, related to whom a number of benefits and problems has also been identified. However, a careful consideration of teachers' role as intermediaries in IT design with children is still missing in the IDC literature. For such, the existing IS and HCI research offers useful insights, enabling a systematic and nuanced examination of the topic.

This paper contributes by exploring ways by which teachers act as intermediaries in design processes with children. By examining three of our previous projects in which we have carried out design together with children and their teachers, we identify a number of activities teachers have been involved in as intermediaries as well as different roles teachers have adopted in the design process with children.

Citation: Iivari, Netta \& Kinnula, Marianne (2016) 'It Has to Be Useful for the Pupils, of Course' - Teachers as Intermediaries in Design with Children. 7 Scandinavian Conference on Information Systems (SCIS), August 7-10, 2016, Ljungskile, Sweden, pp. 16-28. Springer International Publishing.

The final publication is available at http://link.springer.com/chapter/10.1007/978-3-319-43597-8 2 
Iivari and Kinnula (2016) - This is an author version of the accepted article

Next, we review the existing IDC literature addressing IT design with children and teachers' role in that. Thereafter, we present an analytical lens for making sense of the intermediary position of teachers, built on the existing IS and HCI literature. Then, the research design and cases involved in this study are described, after which the empirical results are outlined. We conclude by summarizing the results, discussing their implications and limitations, and identifying paths for future work.

\section{IT design with children and teachers}

In IDC research the main aim is to create high quality IT for children, with children [33]. Especially children's participation in IT design has gained attention. The significance of the school context and teachers in design work with children has also been acknowledged long ago. Especially when designing or evaluating educational technology, school environment is a natural field setting and teachers a suitable expert group to be involved [7][22][23][27][32]. More generally, IDC researchers have recognized that teachers are 'significant adults' in children's lives [4][21][24]. Teachers are needed for allowing design sessions in their classrooms [6]. This may involve teachers making changes into their teaching plans [4][6]. Collaboration with teachers is important for fitting the design activities with the existing curriculum so that the classroom time can be justified [4][7][28].

Part of the IDC community is relatively critical regarding teachers' participation: they warn that teachers' participation may hamper children's possibilities to take part in design as equal members [3][4][5][9]. Teachers usually are in charge in the classroom and children are used to following orders and being tested by teachers, and this may be detrimental from the viewpoint of design in which everyone's expertise is to be valued on an equal basis and all are to contribute equally [3][4][5][9]. Because of this, there have been suggestions for changing the power structures between teachers and children e.g. by placing the design activities somewhere else than school, or by letting children start projects before teachers and thus to become 'experts', able to teach teachers when they join the projects [6]. A similar type of approach has also been utilized when giving children a possibility to teach teachers in use of new IT [22].

Positive findings regarding teachers' role in the design process can also be found. Teachers can be invited as informants or evaluators into the design process: they can offer information for the basis of defining suitable learning goals for a design solution, and they can evaluate achievement of those later on [23][29][32]. Teachers can also take care of practical arrangements [25] and help children to focus on design tasks [19][20][22]. They can collect data [4] and help children and designers to understand each other [19][20][22]. They can comment on the planned activities and used language [19][23][26][28] and participate in evaluating project results [20].

\section{Analytical Lens}

In the existing IS and HCI research, intermediaries have been called for to cater for users' needs and to facilitate user participation in the design process [13][14] [30][31]: e.g. in the HCI literature HCI professionals have been positioned as needed advocates of users, who are to 'represent the user' both in presentational and political senses, i.e. to know the users and deliver this knowledge to design and to speak if not fight for the user in the design process, as well as to facilitate collaboration among users and designers [1][2][10][11][12][13]. In the Computer Supported Cooperative Design (CSCW) literature, ethnographers have been seen as essential for systems design: they are to acquire thorough understanding of users' work practices through their ethnographic fieldwork and to communicate this understanding to the design [15]. In the CSCW literature, user advocates, i.e. people having thorough understanding of users, have also been called for to 'speak for the users' in the development [17]. In the IS literature, change agents have been called for to enable and facilitate user participation [18]. Clearly divergent positions can be identified, however: while the mainstream IS literature argues for enabling and facilitating user participation to serve the needs of the organization and the management, critical IS literature influenced by the Scandinavian tradition calls for facilitating user participation for the purpose of emancipating the users and for combating the organization and management goals [31].

Particularly HCI professionals' intermediary position between users and developers has received attention during the past years. In addition to different activities these intermediaries are to perform in the design process (see above), the literature has also identified a number of HCI professionals' roles in the design process: they have been positioned as informants, evaluators, design participants, or authoritative designers [11]. In an informant position, HCI professionals merely offer information for developers; the information may be based on their empirical user studies or on some general $\mathrm{HCI}$ theory or guidelines. As evaluators, $\mathrm{HCI}$ professionals comment on the design solutions, again relying on their empirical user feedback or some general HCI guidelines. However, HCI professionals may also be invited into design 
Iivari and Kinnula (2016) - This is an author version of the accepted article

teams as active participants, having some decision-making power. On some occasions, HCI professionals may even be allowed to act as actual, authoritative designers, having the power to make influential design decisions regarding the design solution. [11]

As a summary, various kinds of intermediaries have been recommended for 'representing the user' in the design process and for enabling users' participation. Some of them are expected to offer understanding of users to designers (e.g. HCI professionals, ethnographers), others to stand for or to speak on behalf of users during the design process (e.g. HCI specialists, user advocates), while some are to facilitate cooperation among users and designers during the design process (e.g. HCI professionals, IS change agents) [31]. Equipped with these tools and distinctions, we will make sense of teachers' roles and contribution as intermediaries in the design process with children.

\section{Research design}

This study was initiated in cooperation with a national LUKUINTO ("Joy of Reading") programme in Finland, to encourage children to increase their literacy skills and interest in reading. IS/HCI researchers were invited to contribute. They, together with their Masters' level students, initiated small-scale research and development projects, which also included representatives from the LUKUINTO programme and local schools, including some teachers and pupils. The projects included designing games for young people for the purpose of increasing their literacy skills and reading interest, while later the focus was broadened to educating children in game design and more generally in IT design. In this paper, we study three projects. They are similar in many respects but also offer versatility as regards possible teacher roles and activities as one was organized during the LUKUINTO programme, while two have been conducted afterwards with teachers initiating the cooperation.

\subsection{Project A}

The project was initiated by the IS/HCI researchers and the LUKUINTO representatives and it aimed to increase the literacy skills and reading interest of children by letting children design a game, to develop a game editor to enable children to develop games and to educate and empower children in IT design. It was essential to allow children to participate as much as possible. A teacher volunteered to take part and she was invited into the steering group of the project. The project work was part of normal schoolwork for the pupils: it was integrated into their Finnish language lessons.

The participants were one class of 7" graders (13-14 years) in a local comprehensive school. The Masters' level students worked extensively with the class: they organized workshops on game ideation, design, evaluation and editor evaluation. The children acted as design partners and evaluators.

Data of the project includes multimodal data of workshops with children, game and editor development related data, project management data, results reports, short interviews with children, and a teacher interview.

\subsection{Project B}

This project was initiated after the LUKUINTO programme ended. A teacher familiar with the work of the IS/HCI researchers initiated cooperation. A Masters' level student project was established. The teacher acted as the customer and set the project aims: to develop a game supporting children's learning in different school subjects (history, English language, Finnish as native language) and to involve children as much as possible in game development. The teacher chose the theme of the game so that it served children's learning related to the historical phenomenon of immigration and made collaboration between different school subjects possible. Several teachers responsible for these subjects were involved in the project, while the customer teacher was part of the steering group of the project. The project work was integrated in the normal schoolwork of the pupils.

Altogether, $588^{*}$ graders (13-14 years) and 37 7 graders (12-13 years) from different classes from a local comprehensive school took part in the study. All $7^{\text {" }}$ and $8^{\text {" }}$ graders took part in game design. They created the base story for the game that the Masters' level students implemented. In addition, they created mini-games to complement the main

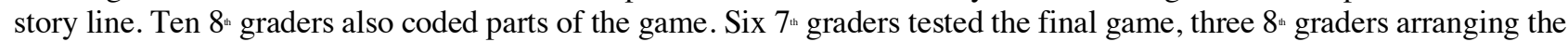
tests. The game is currently in use at the school history and English subject classes for $7^{\text {ti }}$ and $8^{\text {n }}$ graders. Overall, the children acted as design partners and evaluators of the new game, and as participatory designers when arranging the tests for the younger children. 
Iivari and Kinnula (2016) - This is an author version of the accepted article

Data of the project includes game development related data, interviews of $8^{m}$ graders arranging the testing of the game, project management data, results reports, and two teacher interviews.

\subsection{Project C}

This project was also initiated after the LUKUINTO programme ended. One of the students from a previous Masters' level student project had been hired into a local comprehensive school and he advertised the possibility of organizing such projects. A teacher initiated cooperation and a Masters' level student project was again established. The teacher as the customer set the project aims: to develop a game based on a Finnish national epic to support children's literacy skills and reading interest, and to involve children in game development as much as possible. The teacher and the former Masters' student working in the school were part of the steering group. The work was integrated with Finnish language lessons and was part of normal schoolwork for the pupils.

Altogether, 20 9" graders (14-15 years) and $78^{\text {" }}$ graders (13-14 years) from different classes from a comprehensive

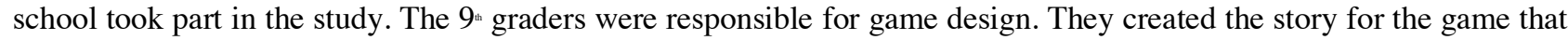
the Master's level students implemented. The $9^{\text {m }}$ graders evaluated the game and then invited seven $8^{\text {n }}$ graders to test the final game, the $9^{\text {m }}$ graders arranging the tests. Overall, the children acted as design partners and evaluators of the new game and as participatory designers when arranging the tests for the younger children.

Data of the project includes game development related data, project management data, results reports, and two teacher interviews.

\subsection{Data analysis}

When analyzing the data, we went through the project documentation of all the three projects and collected and categorized information based on the analytic lens developed in section 3. The focus was on locating evidence on the activities and roles of the teachers in the projects. First an analysis was carried out on each project separately, after which the data was combined to form an overall understanding. The data was abstracted to a table form for synthesis and comparison. During this phase, the data was also extensively discussed to ensure that we agreed with the interpretations.

\section{Empirical insights}

In Figure 1, teachers' activities as intermediaries are summarized.

Delivering general understanding of children. The teachers contributed to the design process through 'knowing children' and through delivering this understanding to the design process. Teachers have a general understanding of children - their development and education related issues - based on their teacher education and experience. In Finland, the qualifications required from teachers are defined in the legislation. All teachers in general education hold a Master's degree and have pedagogical training. This provides a very useful basis for considering which kind of tasks suit children and their development. As an example, a teachers wars about working with teenagers: "When teenagers are involved, (...) anything can happen. Most likely they behave well, but you can get any kind of feedback." (Project C)

Delivering empirical understanding of children. Teachers also know their pupils as individuals. This may also be very valuable information for the design process. Teachers can utilize this, e.g., when dividing children into groups or when selecting children for certain tasks: "I know the pupils and how to make certain pupils work and get excited." (Project C) "The class selected into this project is very good ability-wise, so they can work effectively during those lessons where teaching must be condensed so that there is time for the game work." (Project A) "The teacher selects the test persons to avoid e.g. a situation where people are laughing at others' creations." (Project C) 
Iivari and Kinnula (2016) - This is an author version of the accepted article

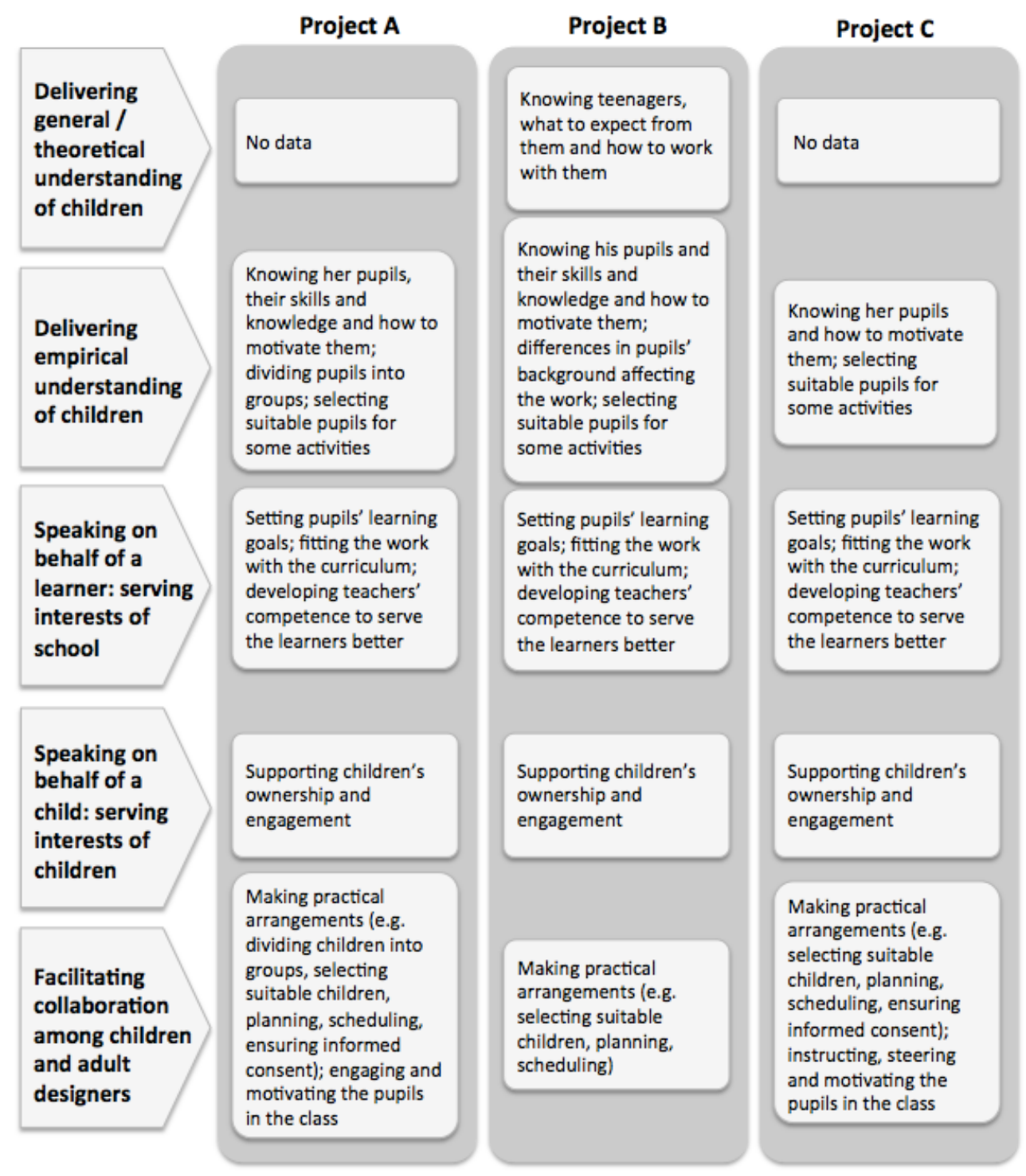

Fig. 1. Intermediary activities of the teachers

Speaking on behalf of a learner: serving the interests of school. The teachers acted also as advocates for children's learning. They considered the design work from the perspective of the curriculum and the learning goals of the pupils. The teachers considered these goals as very valuable for the children and tried to ensure they were met: "Teacher has the pedagogic responsibility of children learning what they are supposed to learn. (...) The challenges concern specifically scheduling. In the final year of the curriculum there are many different language, literature, and media related issues that should be integrated into the project. Otherwise it would not be possible to spend so many lessons on dealing with one classic." (Project C) Some of the learning goals set by teachers were specific to certain school subjects (history, project B; Finnish language, Project C). However, the learning goals can also be wider, e.g.: "about game development as well as about working with other people than the teacher only, group work and negotiation skills as well as about the content and meaning of multi-literacies." (Project A) Another important observation is that this was a learning process for the teachers as well, e.g. as regards new methods to use in their teaching: "I joined this eagerly and curiously to gain new perspective for handling a classic (...) I expect the pupils to gain a new kind of learning experience (...) I want to actively experiment with and develop new teaching methods." (Project C) "I would like to learn as much as possible about multidisciplinary collaboration and project management." (Project B). At the end of the day, all this should still serve the interests of the learner: "it has to be useful for the pupils, of course." (Project B).

Speaking on behalf of a child: serving the interests of children. The teachers can be argued to advocate children's own interests too, to an extent. Project A relied heavily on children's interests as children were allowed to select the game 
Iivari and Kinnula (2016) - This is an author version of the accepted article

theme, whereas in other projects it was defined by the teachers. Children's participation and ownership as regards the project and its outcome were nevertheless considered important: "[It is important that] children feel that the game was made by themselves." (Project C) "It has been positive to see the excitement of the pupils (...) For many, traditional Finnish language lessons are not so interesting, so it has been great to see how excited they have been about this." (Project A) In Project B the teacher also highlighted how important it is to advertise the results to other pupils: "It would be important to let all try out the first version [of the game] to make the pupils' contribution visible. All [other] pupils could be informed about this project." The teachers wanted the children to feel personally "rewarded' in the projects. However, from the perspective of critical tradition, children need to be empowered to combat their oppressors and the organization and management goals. Our projects did not include any evidence of the teachers speaking on behalf of children in this critical sense, however.

Facilitating collaboration among children and adult designers. The teachers also were a useful resource during the actual design sessions: they know how to motivate, inspire, and handle children and how to make things happen in the classroom: "Teacher does a lot of pre-work with children so that everything happens smoothly and efficiently when [designers] enter the school and work with children (...) We decided together with [a former Master's student] that we hide the coloring pens in a closet as some pupils concentrated on coloring and not on what they were expected to. Some pupils were like: 'what, can't I color', but we were tough." (Project C) "The teacher mainly supported [working], walking among the pupils. (...) The interest was attempted to be aroused after the break with 'spies', according to [the teacher's] advice. One person was selected from every group to ['spy'] the outcomes of the other groups." (Project A) The teachers were also active in ensuring that informed consent was gained from the parents. Teachers were also involved in selecting children for some activities: "Pupils were selected with the help of the teacher. The project group asked for eager pupils as testers" (Project A).

In Figure 2, teachers' roles in the design process are summarized.

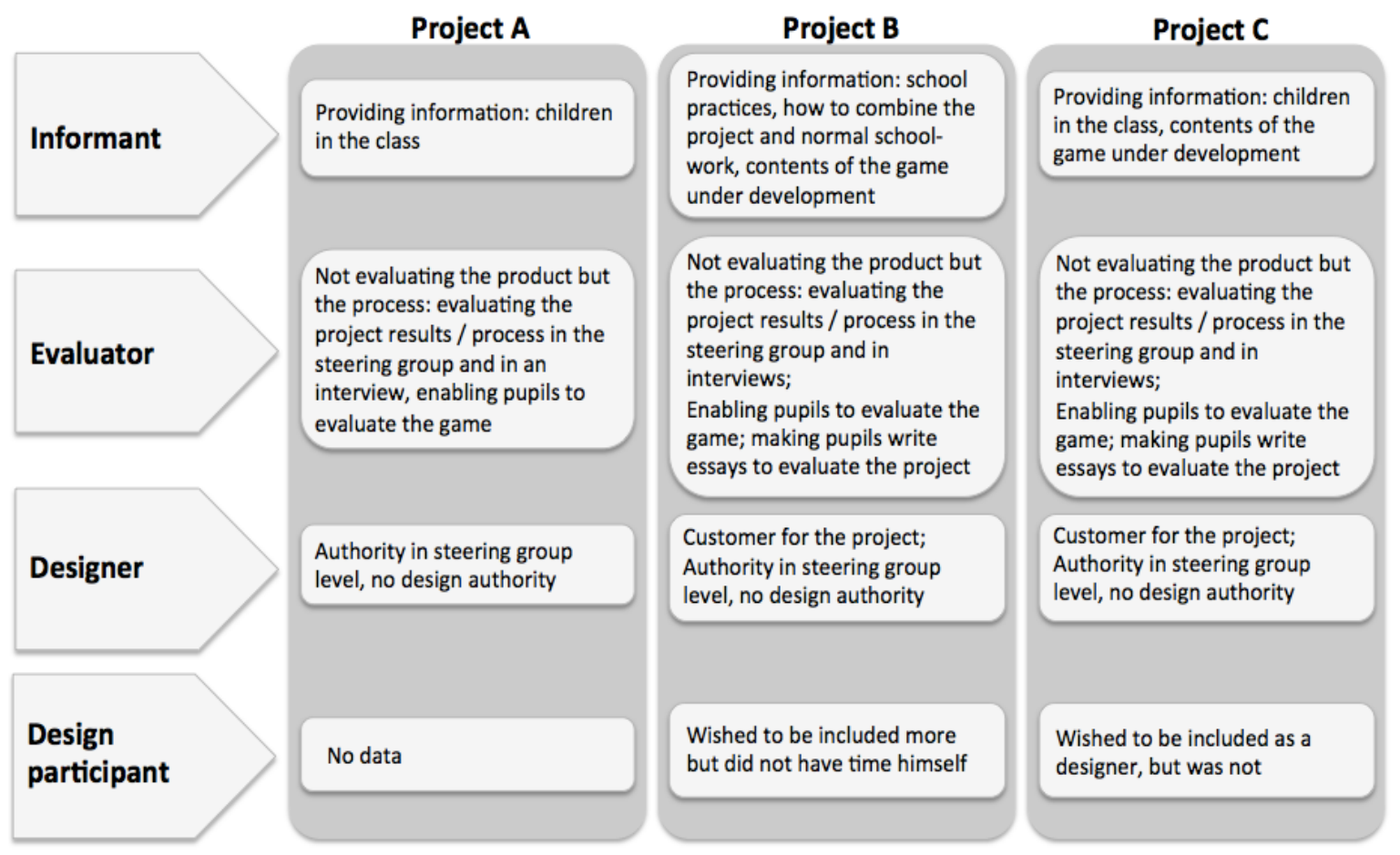

Fig. 2. Intermediary roles of the teachers

Acting as an informant. The teachers clearly acted as informants in the projects, offering information about children for the design team: general information about the particular age group as well as specific information about their pupils. Moreover, they offered information for the basis of the design work, i.e. what they wanted the developed games to make children learn, i.e. contents of the national epic, or history. They also gave designers a lot of information of good working practices with school and how to plan the collaboration projects.

Acting as an evaluator. Moreover, the teachers acted as evaluators of the process. They were interviewed during the project and they were also members of the steering groups of these projects, through which they were inevitably evaluating 
Iivari and Kinnula (2016) - This is an author version of the accepted article

the progress and the outcome of the projects. Teachers also have a lot of expertise related to evaluating learning and that definitely could have been utilized more in the projects. Two of the teachers actually asked children to write essays related to their game development experiences after the projects had ended, thereby inviting children to reflect on and evaluate their learning. We could have invited the teachers to evaluate the developed games and to plan the evaluation of the process in collaboration with us, so that their valuable expertise would have been utilized better.

Acting as a design participant. The teachers did not act as design participants in the game design process. We did not even consider this option; however, the teacher in Project $C$ specifically pointed out that she would have liked to take part in the design work: "Would it be possible to include the teacher [in game development], my fingers were itching to make speech bubbles." The teacher in Project B also mentioned his wish to take part and understand the game development process better. This could be taken into account in our future projects better as well.

Acting as a designer. The teachers obviously were not in an authoritative designer position, as they were not involved in game design at all. On the other hand, they had a lot of authority and decision-making power as customers and steering group members in the projects: they were planning, steering, and making decisions in collaboration with us. In this position they can be considered acting as representatives of schools, pupils, and learning. However, we could prepare and support them much better in acting in this position. More explicit and systematic invitation of teachers into this kind of representative position could be useful.

\section{Concluding discussion}

In this paper we explored the ways in which teachers act as intermediaries in design process with children. We applied an analytical lens from existing IS and HCI research, within which a variety of intermediaries have been identified for catering for users' needs and enabling user participation, to three of our previous game design projects, conducted in collaboration with schoolchildren and their teachers. Our analysis shows that teachers acted as intermediaries in design processes with children in various ways. They offered valuable understanding of children through their general knowledge about child development as well as through their knowledge of their class. They also acted as advocates of pupils and their learning. They especially considered children's learning goals and the project fit with the curriculum and also developed their own skills and knowledge to be able to serve the children and their learning even better. On some occasions they also seemed to act as advocates of children's interests more generally, e.g. when they highlighted how important it is for children to feel ownership of the outcome and celebrated children's interest and engagement in the design work. However, the teachers did not act as children's advocates in the sense of critical tradition, which would have necessitated advocating the empowerment of children to combat the organization and management goals, i.e., the school and learning goals in this case. Then again, the teachers acted as valuable facilitators in the design process: they made many practical arrangements and motivated, encouraged, steered, and instructed children during the design work. Overall, the teachers acted as informants and evaluators in the design process, but they did not act as design partners or authoritative designers in actual game design. However, they were active decision-makers as regards the goals and workings of the projects on a more general level.

We contribute to the existing literature addressing the position and contribution of teachers in IT design with children through offering a systematic and nuanced examination of teachers' roles and activities that was inspired by the IS and $\mathrm{HCI}$ literature on intermediaries in IT design. This study gives names to the issues that have been reported also previously but that have not been treated explicitly or systematically.

Overall, we maintain that we should try to take better advantage of the skills and competencies of teachers when organizing our design projects. Teachers can be considered as valuable intermediaries in IT design with children as they, e.g.:

Have developmental knowledge of children: what is difficult/easy/suitable for children at particular age/stage of development [9]

- Have intimate knowledge of their pupils: of their background, homes, life situations, preferences, skills, and knowledge [21]

Have knowledge of how to work with children (e.g. encourage, motivate, steer, instruct) [19][20][22][23][26][28]

Can fit design work with meaningful learning goals and the curriculum [4][6][7]

Are experts in the evaluation of learning and can thus help in defining project goals and metrics for evaluating the achievement of those [20][23][29][32]

Want children's best; learning-wise but also more generally related to helping children to grow into better persons

However, we acknowledge that teachers' participation in IT design with children can also be criticized. Teachers may hamper the design process as they, e.g.: 
Iivari and Kinnula (2016) - This is an author version of the accepted article

- May make children conform to hierarchies and usual ways of working in the school context, hindering children's creativity and design contribution [3][4][5][9]

Do not necessarily know much about IT and design [22][27][28] and thus may misunderstand the project aims and guide the project towards wrong direction

In our projects the teachers carried out the activities and adopted the roles without any explicit assignment or request. On the other hand, many of them are quite natural for teachers to adopt: to offer understanding of children to designers, to speak on behalf of children's learning in the project, and to facilitate cooperation among users and designers in the classroom. However, the teachers were not experts in IT design and they would not have been able to plan the activities and roles in advance, but those just emerged ad hoc, in situ. We did not plan for them either, but appreciated them after the fact. It seems that teachers are quite well equipped for acting as intermediaries in IT design with children; however, the work would surely have benefitted from a more explicit and systematic approach to it. Moreover, empowering children to combat their oppressors was not something that the teachers advocated; rather, they advocated the management and organization goals in the sense of the school and the curriculum. Some other intermediaries may be needed to take care of children's empowerment in the critical sense, if that is considered as significant in a design project.

The intermediaries 'representing the user' in industry have been criticized for lacking power to make design decisions [10][11], i.e. they mainly occupy weak informant and evaluator positions. The teachers actually occupied very powerful positions as steering group members, shaping the project goals and workings according to their agendas and interests. Hence, the teachers had their own interests and agendas, too; they were not merely representing the children. Due to this, children are the ones who actually should gain more decision-making power in design projects, to develop their agency and to empower them to have a say in issues concerning their life, instead of teachers, who already occupy quite a powerful position in school and in relation to pupils. Hence, empowering teachers is not our main goal. However, we hope that by empowering teachers and by giving them new tools and understanding for their central purpose, i.e., being useful to the pupils and serving children's learning, we also empower children a bit.

Moreover, as some teachers were eager to join in as game designers, we should in the future consider inviting them as participants into the design process. However, we might have limited time and resources to teach teachers what we expect from adults working as design partners with children. Thus, we need to consider very carefully what kind of tasks and task assignments we use and how we explain to the teachers how this kind of design work is different to normal schoolwork.

We observe many similarities between the work of teachers and the other intermediaries discussed in the literature [13][14][15][18][22][30][31]. Our results may bear relevance for other design contexts, too. For example in the case of health IT, in addition to designers and users, there may be e.g. healthcare professionals, relatives and friends, social workers and educationists available and needed to carry out the activities and adopt the roles the teachers did in our projects. We suggest that both researchers and practitioners reflect on our results in their design contexts and consider whether they can utilize them when planning and implementing their projects. Awareness and use of these concepts may help in formalizing the intermediary position and making conscious choices between different possibilities.

Future research is definitely needed to understand and appreciate the variety of intermediaries and their contribution in IT design. This study was based on three small-scale projects with many limitations and specifics. One clear limitation is that the children's voices were not really heard in this study. In the future, studies scrutinizing teachers' role in IT design with children should be carried out from the children's perspective. In addition, in this study a set of teachers' roles and activities were identified, but likely even more variety could be identified in other settings. Nevertheless, we think that we succeeded in illustrating interesting versatility in the teachers' intermediary position in IT design with children.

\section{Acknowledgements}

We thank the teachers, pupils, Master's level students and LUKUINTO programme representatives for participating in this study. Especially we thank Tonja Molin-Juustila for her contribution.

\section{References}

1. Bødker, S., Buur, J.: The Design Collaboratorium - a Place for Usability Design. ACM Transactions on Computer-Human Interaction 9(2), 152--169 (2002) 
Iivari and Kinnula (2016) - This is an author version of the accepted article

2. Cooper, C., Bowers, J.: Representing the users: Notes on the disciplinary rhetoric of human-computer interaction. In: Thomas, P. (ed.): the Social and Interactional Dimensions of Human-Computer Interfaces, pp. 48--66. Cambridge University Press, Cambridge (1995)

3. Druin, A.: Cooperative Inquiry: Developing New Technologies for Children with Children. In: Proc. CHI, pp. 592--599 (1999)

4. Druin, A.: The Role of Children in the Design of New Technology. Behaviour and Information Technology 21(1), 1--25 (2002)

5. Druin, A., Bederson, B., Boltman, A., Miura, A., Knotts-Callahan, D., Platt, M.: Children as our Technology Design Partners. In: Druin, A. (ed.): The Design of Children's Technology, pp. 51-72. Kaufmann, San Francisco (1998)

6. Druin, A., Bederson, B., Hourcade, J., Sherman, L., Revelle, G., Platner, M., Weng, S.: Designing a digital library for young children: An intergenerational partnership. In: Proc. ACM/IEEE Joint Conference on Digital Libraries, pp. $398--405$ (2001)

7. Garzotto, F.: Broadening children's involvement as design partners: From technology to "experience". In: Proc. IDC, pp. 186-193 (2008)

8. Greenbaum, J., Kyng, M. (eds.): Design at Work. Cooperative Design of Computer Systems. Lawrence Erlbaum Associates, New Jersey (1991)

9. Guha, M., Druin, A., Fails, J.: Cooperative Inquiry Revisited: Reflections of the Past and Guidelines for the Future of Intergenerational Co-design. International Journal of Child Computer Interaction 1(1), 14-23 (2013)

10.Gulliksen, J., Boivie, I., Göransson, B.: Usability professionals - current practices and future development. Interacting with Computers 18(4), 568-600 (2006)

11.Iivari, N.: Understanding the Work of an HCI Practitioner. In: Proc. NordiCHI, pp. 185-194. (2006)

12.Iivari, N.: Culturally Compatible Usability Work - An Interpretive Case Study on the Relationship between Usability Work and Its Cultural Context in Software Product Development Organizations. Journal of Organizational and End User Computing 22(3), 40-65 (2010)

13.Iivari, N.: Usability Specialists as Boundary Spanners-An Appraisal of Usability Specialists' Work in Multiparty Distributed Open Source Software Development Effort. In: Proc. INTERACT, pp. 571-588 (2013)

14.Iivari, N., Karasti, H., Molin-Juustila, T., Salmela, S., Syrjänen, AL., Halkola, E.: Mediation between design and use - revisiting five empirical studies. Human IT - Journal for Information Technology Studies as a Human Science 10(2), 81-126 (2009)

15.Karasti, H.: Increasing Sensitivity towards Everyday Work Practice in System Design. Acta Universitatis Ouluensis, Scientiae Rerum Naturalium A 362. Oulu University Press, Oulu (2001)

16.Kyng, M.: Bridging the Gap between Politics and Techniques: On the next practices of participatory design. Scandinavian Journal of Information Systems, 22(1), 49-68 (2010)

17.Mambrey, P., Mark, G. Pankoke-Babatz, U.: User advocacy in participatory design: Designers' experiences with a new communication channel. Computer Supported Cooperative Work, 7(3-4), 291-313 (1998)

18.Markus, M., Mao, Y.: User Participation in Development and Implementation: Updating an Old Tired Concept for Today's IS Contexts. Journal of the Association for Information Systems 5(11-12), 514-544 (2004)

19.Mazzone, E., Iivari, N., Tikkanen, R., Read, J., Beale, R.: Considering context, content, management, and engagement in design activities with children. In: Proc. IDC, pp. 108-117 (2010)

20.Mazzone, E., Read, J., Beale, R.: Design with and for disaffected teenagers. In: Proc. NordiCHI, pp. 290-297 (2008)

21.Molin-Juustila, T., Kinnula, M., Iivari, N., Kuure, L., Halkola, E.: Multiple voices in ICT design with children - a nexus analytical enquiry. Behaviour \& Information Technology 34(11), 1079-1091 (2015)

22.Pardo, S., Vetere, F., Howard, S.: Broadening Stakeholder Involvement in UCD: Designers' Perspectives on Child-Centred Design. In: Proc. OzCHI, pp. 1-9 (2005)

23.Pardo, S., Vetere, F., Howard, S.: Teachers' Involvement in usability testing with children. In: Proc. IDC, pp. 89-92 (2006)

24.Read, R., Bekker, M.: The nature of child computer interaction. In Proc. BHCI, pp. 163-170 (2011)

25.Read, J., Gregory, P., MacFarlane, S., McManus, B., Gray, P., Patel, R.: An investigation of participatory design with childreninformant, balanced and facilitated design. In: Proc. IDC, pp. 53-64 (2002)

26.Read, J., MacFarlane, S.: Using the fun toolkit and other survey methods to gather opinions in child computer interaction. In: Proc. IDC, pp. 81-88 (2006)

27.Robertson, J.: Experiences of designing with children and teachers in the StoryStation Project. In: Proc. IDC, pp. 29-41 (2002)

28.Rode, J., Stringer, M., Toye, E., Simpson, A., Blackwell, A.: Curriculum-focused design. In: Proc. IDC, pp. 119-126 (2003)

29.Scaife, M., Rogers, Y., Aldrich, F., Davies, M.: Designing for or designing with? Informant design for interactive learning environments. In: Proc. CHI, pp. 343-350 (1997)

30.Simonsen, J., Robertson, T. (eds.): Routledge international handbook of participatory design. Routledge, New York (2013)

31.Tuovila, S., Iivari, N.: Bridge Builders in IT Artifact Development. In: Proc. ECIS, pp. 819-830 (2007)

32.Virvou, M., Tsiriga, V.: Involving effectively teachers \& students in the life cycle of an intelligent tutoring system. Educational Technology \& Society 3(3), 511-521 (2000)

33.Yarosh, S., Radu, Y., Hunter, S., Rosenbaum, E.: Examining values: an analysis of nine years of IDC research. In: Proc. IDC, pp. 136-144 (2011) 